\title{
Spatial Distribution of Ca Currents in Molluscan Neuron Cell Bodies and Regional Differences in the Strength of Inactivation
}

\author{
Stuart Thompson and Julie Coombs \\ Hopkins Marine Station, Stanford University, Pacific Grove, California 93950
}

The spatial distribution of Ca current in molluscan neuron cell bodies was studied using a large patch method in combination with 2-microelectrode voltage clamp. The method has a spatial resolution equal to about $0.1 \%$ of the cell body area. Ca current is not uniformly distributed. The current density varies between patches, changing by as much as a factor of 2.5 over a distance of $20 \mu \mathrm{m}$, and there is evidence that Ca current occurs in 'hot spots" involving a few hundred channels. The current density increases in a moderately steep gradient from the soma cap, opposite the axon, toward the axon hillock.

Ca currents in patches from different regions of the soma are qualitatively different. Currents near the soma cap do not inactivate or inactivate weakly during depolarization, while currents of equal density nearer the axon hillock exhibit pronounced inactivation. The strength of inactivation increases in parallel with the gradient in current density, but local differences in current density, or in the number of active $\mathrm{Ca}$ channels, do not explain the variability in inactivation. Inactivating and noninactivating $\mathrm{Ca}$ currents could not be distinguished on the basis of activation or deactivation kinetics, voltage dependence of activation, or sensitivity to hyperpolarizing conditioning pulses. Also, the amplitude of noninactivating current near the soma cap is reduced by intracellular $\mathrm{Ca}$ injection showing that, like the whole-cell current, $\mathrm{Ca}$ current in this region is subject to Ca-dependent inactivation. The data favor the hypothesis that these cells express only one type of Ca channel. Differences in the strength of inactivation may result from local differences in cytoplasmic $\mathrm{Ca}$ buffering, local modification of $\mathrm{Ca}$ channels in a way that changes their sensitivity to Ca-dependent inactivation, or local differences in the availability of cytoplasmic factors or enzymes that are necessary for inactivation.

Individual neurons, muscle cells, and oocytes can simultaneously express several types of $\mathrm{Ca}$ currents that differ in voltage dependence and kinetics and may play different roles in the biology of the cell (I Iagiwara et al., 1975; Tsien, 1983; Carbone and Lux, 1984a, b; Bean, 1985; McCleskey et al., 1986; Miller, 1987; Narahashi et al., 1987). We wanted to know if the several types of Ca currents have different patterns of spatial distribution on the cell surface. The data collected in pursuing this

\footnotetext{
Received Apr. 16, 1987; revised Sept. 21, 1987; accepted Oct. 19, 1987.

We thank R. Aldrich and B. Premack for suggestions and the staff of the Hopkins Marine Station for assistance. Work supported by PHS Grant NS14519 to S.T.

Correspondence should be addressed to Stuart Thompson at the above address.

Copyright (C) 1988 Society for Neuroscience $0270-6474 / 88 / 061929-11 \$ 02.00 / 0$
}

question raise the possibility that the same species of Ca current can perform differently depending on location.

Large patch current recording in combination with 2-microelectrode voltage clamp was used to map the spatial distribution of $\mathrm{Ca}$ current on the cell bodies of molluscan neurons. $\mathrm{Ca}$ current is found in all regions of the soma, but the current is not uniformly distributed and the average current density increases moderately from the soma cap to the axon hillock. Unexpectedly, Ca currents recorded from different regions have qualitatively different properties. Currents recorded near the soma cap do not inactivate or inactivate only weakly during depolarization, while currents recorded nearer the axon hillock exhibit strong current-dependent inactivation like that observed in whole-cell voltage-clamp experiments (Kostyuk and Krishtal, 1977; Tillotson, 1979; Eckcrt and Tillotson, 1981; Hagiwara and Byerly, 1981; Byerly and Hagiwara, 1982; Eckert and Chad, 1984). The voltage dependence and kinetics of inactivating and noninactivating Ca currents were compared, and the results favor the hypothesis that the same type of Ca channel is expressed at all locations. Mechanisms that might give rise to local variability in the strength of inactivation are discussed. A brief report of this work has appeared (Thompson and Coombs, 1986).

\section{Materials and Methods}

Identified neurons were isolated from the pedal and pleural ganglia of the molluscan species Anisodoris nobilis and Doriopsilla albopunctata. The ganglia were treated with neutral protease (Dispase; $1 \mathrm{mg} / \mathrm{ml}$ for 1 $\mathrm{hr}$ at $15^{\circ} \mathrm{C}$ ) to soften the connective tissue sheath before dissection. A small group of cells was axotomized and removed from the ganglia after undercutting the cell bodies with iris scissors and transferred to a temperature-controlled stage maintained at $15^{\circ} \mathrm{C}$. There was no evidence of escape during voltage-clamp depolarization in successfully isolated cells, indicating that the cell body and axon remnant are adequately space clamped. A second method for evaluating cell body isolation is described below. We concentrated on the 3 largest neurons in the pedal ganglia. These cells have similar firing properties and express the same types of ionic currents in approximately the same proportions.

Voltage clamp and large patch current recording. The method used for 2-microelectrode voltage clamp was described by Barish and Thompson (1983). Micropipettes were filled with $5 \mathrm{M} \mathrm{CsCl}$ and had resistances of 2-6 M 2 . Membrane voltage was measured differentially between an intracellular microelectrode and a voltage electrode in the bath. Whole-cell current was recorded with a virtual ground amplifier connected to the bath by a separate saline-agar bridge.

An extracellular pipette was used to record macroscopic currents from patches of soma membrane. The method was described by Johnson and Thompson (1984) and is similar to that of Strickholm (1961), Frank and Tauc (1963), Neher and Lux (1969), and Stuhmer et al. (1983). The internal diameter at the tip of the pipette was $5-20 \mu \mathrm{m}$, and the pipette resistance was about $100 \mathrm{k} \Omega$. After contacting the cell, gentle suction was applied until the pipette resistance increased to between 20 and $100 \mathrm{M} \Omega$ and then released. Errors in current measurement due to the 
finite resistance of the seal are negligible because the currents are small and the patch electrode is maintained at the bath potential. The seal resistance was checked periodically to insure that it remained constant and care was taken to avoid pulling a finger of membrane into the pipette since this could lead to errors in voltage control due to increased access resistance. Data were accepted only if the area of the patch did not change by more than a few percent over the course of an experiment. Patch current was recorded by a virtual ground circuit referenced to the hath voltage follower in order to correct for changes in bath voltage during large currents. Using this arrangement, the patch pipette could be applied to points from the soma cap to midway between the axon and the equator of the soma. Points nearer the axon hillock could occasionally be reached after aspirating away adherent cells and connective tissue, but this procedure was not used routinely. Appropriately filtered records of membrane voltage, whole-cell current, and patch current were digitized and stored on a laboratory computer (DEC 11/ 23) at adjustable sampling rates.

Current separation. In order to eliminate inward $\mathrm{Na}$ and outward $\mathrm{K}$ currents, the cells were bathed in a saline of the following composition (mM): 300 tetraethylammonium $\cdot \mathrm{Cl}$ (TEA), 104 -aminopyridine (4-AP), $60 \mathrm{CaCl}_{2}, 180$ Tris $\mathrm{Cl}$ (pH 7.8). Barium saline was made by substituting $\mathrm{BaCl}_{2}$ for $\mathrm{CaCl}_{2}$, and salines containing altered $\mathrm{K}$ concentrations were made by substituting $\mathrm{KCl}$ for Tris. $\mathrm{Cl}$. The salines were prepared and the $\mathrm{pH}$ adjusted just before use. We checked for residual $\mathrm{K}$ currents by observing tail currents on the return to $-40 \mathrm{mV}$ after depolarizing pulses. The delayed outward current decays within $1 \mathrm{sec}$ at this voltage, and the $\mathrm{Ca}$-dependent $\mathrm{K}$ current decays over tens of seconds (Thompson, 1977). In the majority of experiments, outward tail currents were not present, and the inward tail currents were insensitive to changes in external $\mathrm{K}$ concentration, confirming the nearly complete block of $\mathrm{K}$ currents. The few cells that did have small outward tail currents were rejected. The block of $\mathrm{Ca}$-dependent $\mathrm{K}$ current was confirmed by iontophoretic injection of $\mathrm{Ca}$ into the cytoplasm from a third microelectrode containing $0.5 \mathrm{M} \mathrm{CaCl}_{2}$. The injection current was monitored and the amount of $\mathrm{Ca}$ injected was calculated assuming a $\mathrm{Ca}$ transport number of 0.5 (Gorman and Thomas, 1980). In each of 10 experiments, Ca injection failed to activate $\mathrm{K}$ current in the whole cell or the patch when the TEA, 4-AP saline was used.

In some experiments, a microperfusion system was used to focally perfuse part of the soma with a Ca current blocking solution (method described by Thompson et al. 1986). The millimolar composition of the blocking solution was as follows: $300 \mathrm{TEA} \cdot \mathrm{C} 1,104-\mathrm{AP}, 50 \mathrm{MgCl}_{2}$, $10 \mathrm{MnCl}_{2}, 180$ Tris. $\mathrm{Cl}$ (pH 7.8).

Measurement of membrane area. The areas of the patch and the whole cell were estimated by measuring capacity currents assuming a unit capacitance of $1 \mu \mathrm{F} / \mathrm{cm}^{2}$. A $20 \mathrm{mV}, 50 \mathrm{~Hz}$ triangle wave voltage command centered on the resting potential was applied to the 2-microelectrode voltage clamp. Membrane capacitance was calculated from the amplitude of the jump in patch or whole-cell current that occurs when the triangle wave changes sign (Neher, 1971; Palti, 1971). The capacitance of the patch is easily measured because the voltage difference between the lumen of the pipette and the bath is negligible, and the access resistance is small so that the current waveform during the triangle voltage command closely approximates a square wave. Measurement of whole-cell capacitance can be more difficult. The remnant of axon that remains after axotomy is typically one soma diameter in length During the triangle voltage command the capacitance of the axon remnant is charged through an axial resistance, and as a result, the wholecell current can exhibit 3 phases when the triangle wave changes sign. The first phase is a large jump in current corresponding to membrane capacitance charged through a low access resistance, for example, the capacitance of the soma membrane. The final phase is a straight line with a small slope that is due to current flowing in the membrane resistance. There may also be an intermediate phase, characterized by a slight curvature, that occurs because the instantaneous change in $d V /$ $d t$ in the soma is spread out in time in the axon remnant. In many cases the whole-cell current demonstrated an instantaneous jump at the vertices of the triangle wave with no intermediate curvature. We interpret this as evidence that the cell body and axon remnant is well spaceclamped. When curvature was present, the following method was used to estimate the whole-cell area. A line was fit to the current during phase 3 and extrapolated back to the time of the jump. Membrane capacitance was calculated from the height of the jump to the extrapolated line. This procedure corrects for the slowly changing capacity current in the axon remnant and provides an improved estimate of surface area. Electrical measurement of surface area is preferred over optical methods because an unknown area of membrane is aspirated into the patch pipette when suction is applied and because the soma is invaginated by glial processes that increase the surface area over that of a sphere of the same overall diameter (Mirolli and Talbott, 1972; Mirolli and Gorman, 1973).

\section{Results}

\section{Spatial distribution of $\mathrm{Ca}$ current}

Figure 1 shows families of $\mathrm{Ca}$ currents recorded simultaneously from the whole cell and from a membrane patch located midway between the axon and the equator of the cell body. The area of the patch is $9 \times 10^{-6} \mathrm{~cm}^{2}$ and equal to about $0.1 \%$ of the cell body area $\left(8.2 \times 10^{-3} \mathrm{~cm}^{2}\right)$. Inward Ca current is first seen with depolarization to $-20 \mathrm{mV}$ and the current activates over approximately the same voltage range in both sets of records. In this example, the $\mathrm{Ca}$ current density in the patch during the pulse to $+20 \mathrm{mV}\left(0.014 \mathrm{~mA} / \mathrm{cm}^{2}\right)$ is equal to the average current density in the soma $\left(0.013 \mathrm{~mA} / \mathrm{cm}^{2}\right)$, but data from other patches, and from different regions of the soma, indicate that $\mathrm{Ca}$ channels are not uniformly distributed.

The uneven distribution of $\mathrm{Ca}$ current in the cell body is illustrated in Figure 2, which shows multiple patch recordings from the same cell. Ca currents were recorded during pulses to $+20 \mathrm{mV}$ at 7 locations using the same patch pipette. The locations of the patches are indicated along with the records of $\mathrm{Ca}$ current density. The current density varies from patch to patch even within the same region of the soma. Figure $2 A-C$, for example, shows currents from 3 patches near the soma cap where the peak current density differed by as much as a factor of 2.5 over a distance of $20 \mu \mathrm{m}$. The waveform of the Ca current is also variable. Currents recorded closer to the axon hillock (for example, Fig. $2, F$ and $G$ ) inactivate more strongly than currents recorded near the soma cap.

The spatial distribution of $\mathrm{Ca}$ current was mapped by dividing the soma into 4 regions and recording patch currents in each region. The cell body is approximately spherical, and the 4 regions correspond to the soma cap, a point $45^{\circ}$ from the cap that we refer to as $45^{\circ} \mathrm{N}$, the equator, and a point midway between the equator and the axon hillock at $45^{\circ} \mathrm{S}$. The peak amplitudes of whole-cell and patch Ca currents were recorded simultaneously during $100 \mathrm{msec}$ pulses to $+20 \mathrm{mV}$ and normalized by area in order to estimate current densities. The ratio of patch current density to whole-cell current density was used in plotting the histograms in Figure 3. A value of 1 on the abscissa means that the current density in the patch is equal to the average current density in the cell body, while larger or smaller values indicate that the patch is enriched or lacking in current relative to the cell body average. Ca current was found in all regions, and there was only one patch in the 77 that were examined in which it was not detected. The histograms show that the Ca current density is lowest near the soma cap and increases as the patch pipette is moved toward the axon hillock. The average current density ratio was 0.45 at the soma cap, 0.50 at $45^{\circ} \mathrm{N}, 0.54$ at the equator, and 0.79 for patches located at $45^{\circ} \mathrm{S}$ (see Table 1). Statistical comparison of the current densities in the various regions showed that they were significantly different (Tukey-Kramer Test; $p \geq 0.05$ ), except for the currents at the equator and $45^{\circ} \mathrm{N}$. There is considerable variability in current density between patches in each region, as shown by the large standard deviations in Table 1, and the histograms are skewed toward the right because in each region there are a few patches with an unusually high current density 


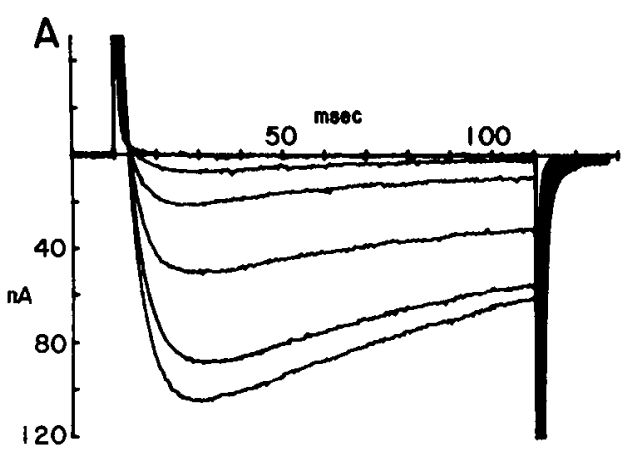

Figure 1. Ca currents recorded simultaneously from the whole cell $(A)$ and a patch $(B)$ located midway between the equator and the axon hillock. Pulses, $100 \mathrm{msec}$, to voltages from -30 to $+20 \mathrm{mV}$ were applied in $10 \mathrm{mV}$ steps from a holding voltage of $-40 \mathrm{mV}$. The interpulse interval was $2 \mathrm{sec}$. Capacity currents and inward tail currents arc truncated. Filter corner frequency, 1 $\mathrm{kHz}$. that represent current "hot spots." It is also apparent that some part of the axotomized cell must have a higher average current density than the regions we explored. The region of higher current density might include the axon hillock, the initial axon segment, or axodendritic branches that remain after axotomy.

\section{Regional differences in Ca current inactivation}

Ca currents near the soma cap inactivate more slowly and less completely than currents nearer the axon hillock. Figure 4 shows $\mathrm{Ca}$ and $\mathrm{Ba}$ currents recorded at several locations on a single neuron. Figure $4 A$ shows the $\mathrm{Ca}$ current density in patches at the soma cap $(\mathrm{C})$, the equator $(\mathrm{E})$, and a point midway between the equator and the axon hillock at $45^{\circ} \mathrm{S}(\mathrm{H})$. Ca currents were recorded during $100 \mathrm{msec}$ pulses to $+20 \mathrm{mV}$ and scaled by membrane area. The peak current density is smallest at the soma cap, somewhat larger at the equator, and much larger at $45^{\circ} \mathrm{S}$. In Figure $4 B$, the same palch currents are scaled to the peak amplitude of the whole-cell current. During the depolarizing pulse, the whole-cell current reaches a maximum and then inactivates as previously described (see Eckert and Chad, 1984). The patch current closest to the axon hillock $(H)$ follows the same time course and overlaps the whole-cell current. In other experiments, patch currents at this location were sometimes found to inactivate more strongly than the average current. In contrast, the $\mathrm{Ca}$ current at the equator $(\mathrm{E})$ inactivates little, and the current at the soma cap (C) docs not inactivate at all during the pulse. The Ca current in the whole cell, therefore, represents the weighted contributions of inactivating and noninactivating currents.

The strength of inactivation at different locations was compared by recording patch currents in the 4 regions of the soma during $100 \mathrm{msec}$ pulses to $+20 \mathrm{mV}$. The ratio of the peak current amplitude to the amplitude after $100 \mathrm{msec}$ was used as a measure of inactivation. A value of 1 means that no inactivation occurs, while a value of 2 indicates $50 \%$ inactivation. The average ratio was 1.2 at the soma cap, 1.12 at $45^{\circ} \mathrm{N}, 1.35$ at the equator, and 2.0 at $45^{\circ} \mathrm{S}$. For the whole-cell current, the average ratio was 2.2 . There was considerable variability in the strength of inactivation between patches within each region, as indicated by the standard deviations in Table 1. For example, in one experiment the Ca current in a patch at the soma cap inactivated by $20 \%$ during the pulse, while the current in an adjacent patch, $20 \mu \mathrm{m}$ away, did not inactivate at all. These findings show that the factors that govern the strength of inactivation act locally, that they are distributed unevenly in the cell, and that the average strength of inactivation increases on going from the soma cap toward the axon hillock.

In molluscan neurons, Ca current inactivation is strongly dependent on the amplitude of the current but nearly independent of membrane potential (Tillotson, 1979; see Eckert and Chad, 1984). At short times, the increase in cytoplasmic Ca concentration due to the activation of Ca channels is restricted to the

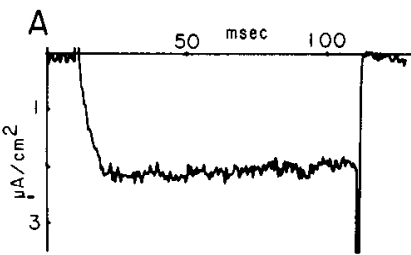

C

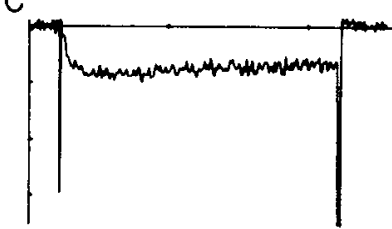

E

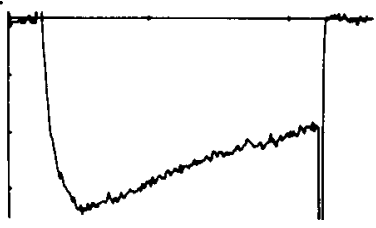

B

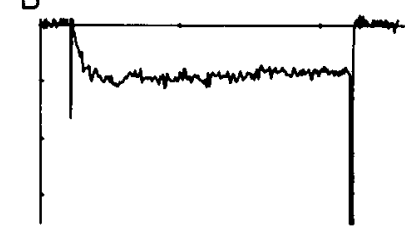

D

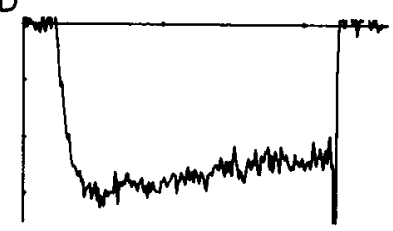

$F$

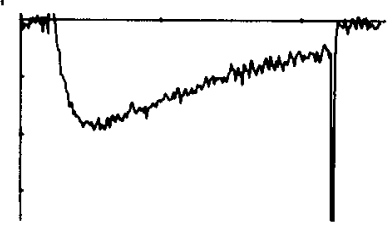

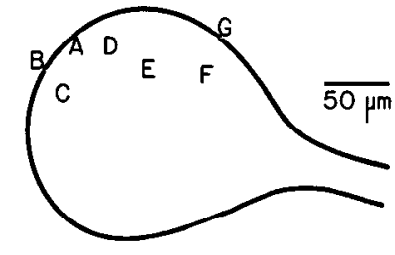

G

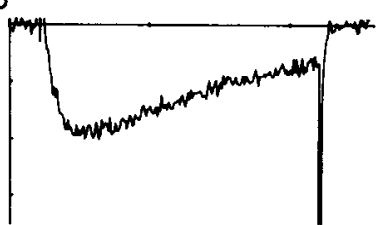

Figure 2. Nonuniform distribution of Ca current in a single cell. Ca currents were recorded from patches at 7 locations using the same $10 \mu \mathrm{m}$ diameter patch pipette. The positions of the patches are shown to the right. Ca currents were activated by $100 \mathrm{msec}$ pulses to $+20 \mathrm{mV}$ from a holding voltage of $-40 \mathrm{mV}$ and normalized by membrane area. Capacity currents and inward tail currents are truncated. Filter corner frequency, $1 \mathrm{kHz}$. 

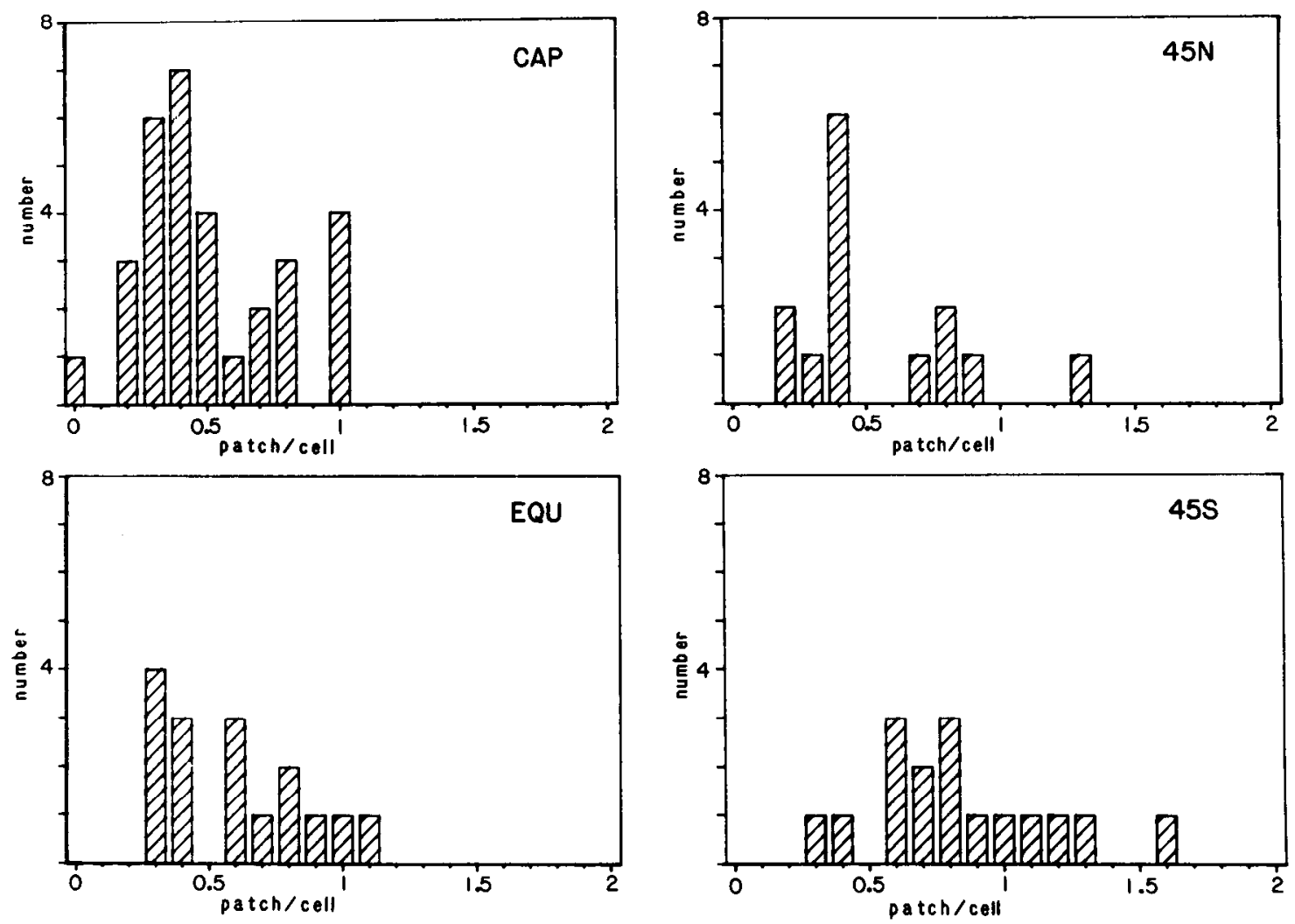

Figure 3. Histograms of the ratio of patch current density to whole-cell current density in 4 regions of the cell body: the soma cap ( $C A P), 45^{\circ}$ from the cap $\left(45^{\circ} \mathrm{N}\right)$, the equator $(E Q U)$, and halfway between the equator and the axon hillock $\left(45^{\circ} \mathrm{S}\right)$. The peak amplitudes of patch and wholecell Ca currents were recorded simultaneously during pulses to $+20 \mathrm{mV}$ from a holding voltage of $-40 \mathrm{mV}$ and scaled by membrane area. A total of 77 experiments were used in constructing the figure.

vicinity of the membrane because of the slow diffusion of $\mathrm{Ca}$ in cytoplasm, the active transport of $\mathrm{Ca}$ out of the cell, and the binding of $\mathrm{Ca}$ to cytoplasmic sites. Because of this, one might expect greater Ca-dependent inactivation nearer the axon hillock simply because the local $\mathrm{Ca}$ current density tends to be higher in that region.

The following experiment was done to test the hypothesis that variability in the strength of inactivation is due to local differences in current density. The amplitude of the depolarizing pulse was varied in order to elicit the same peak $\mathrm{Ca}$ current density in membrane patches at 2 locations on the same cell. Figure $4 C$ shows the current density at the soma cap (C) during a $100 \mathrm{msec}$ depolarization to $+20 \mathrm{mV}$ and the current density at $45^{\circ} \mathrm{S}(\mathrm{H})$ during depolarization to $-10 \mathrm{mV}$. The peak current density is the same at both locations, but the current at the soma cap does not inactivate. This experiment shows that the strength of inactivation is not simply determined by the amplitude of the local current.

Figure 2 illustrated this point in another way. The variability in current density between patches permits comparison of inactivating and noninactivating $\mathrm{Ca}$ currents of equal peak current density during a standard pulse to $+20 \mathrm{mV}$. The current density near the top of the cell in Figure $2 A$, for example, is slightly larger than the peak current densities recorded in 2 patches

\begin{tabular}{|c|c|c|c|}
\hline Location & $\begin{array}{l}\text { Patch } I_{\mathrm{Ca}} \text { density/ } \\
\text { cell } I_{\mathrm{Ca}} \text { density }\end{array}$ & $\begin{array}{l}\text { Average ratio of peak } \\
\text { to steady-state current }\end{array}$ & $\begin{array}{l}\text { Current density } \\
\left(\mathrm{mA} / \mathrm{cm}^{2}\right)\end{array}$ \\
\hline Cap & $0.45 \pm 0.26(31)$ & $1.2 \pm 0.24(31)$ & $0.009 \pm 0.012(23)$ \\
\hline $45 \mathrm{~N}$ & $0.50 \pm 0.30(14)$ & $1.12 \pm 0.09(10)$ & $0.008 \pm 0.003$ \\
\hline Equator & $0.54 \pm 0.24(16)$ & $1.35 \pm 0.23(15)$ & $0.014 \pm 0.010$ \\
\hline $45 S$ & $0.79 \pm 0.32(16)$ & $2.0 \pm 0.25(26)$ & $0.021 \pm 0.016$ \\
\hline All patches & $0.55 \pm 0.30(77)$ & $1.4 \pm 0.27(82)$ & $0.01 \pm 0.01$ \\
\hline Whole cell & - & $2.2 \pm 0.4 \quad(30)$ & $0.02 \pm 0.01$ \\
\hline
\end{tabular}

Values are means + SDs. The ratios of patch Ca current density to cell current density in 4 regions of the soma were obtained from simultaneous current recordings. A value of 1 indicates that the current density in the patch is equal to the average current density in the soma. The average ratio of peak to steady-state current during $100 \mathrm{msec}$ pulses to $+20 \mathrm{mV}$ was used as a measure of the strength of inactivation. The Ca current densities in the last column are the average values for all of the experiments. Number of experiments indicated in parentheses. 
A

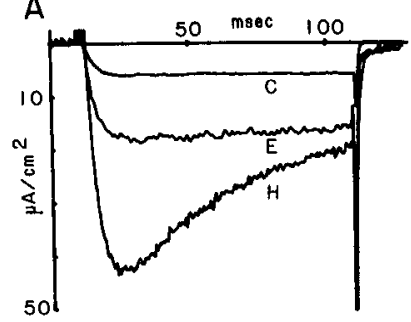

C

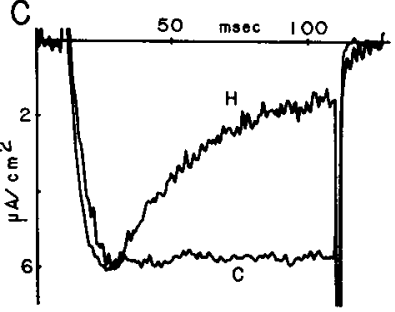

B

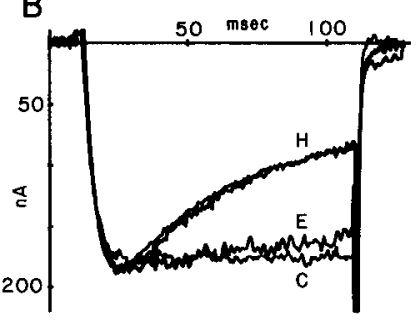

$D$

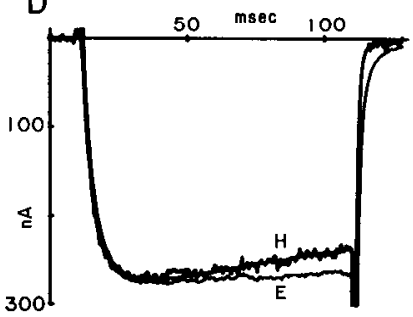

Figure 4. $\mathrm{Ca}$ and $\mathrm{Ba}$ currents at different locations on the same cell. $A$, Ca current densities in 3 patches located at the soma cap (C), the equator $(E)$, and $45^{\circ} \mathrm{S}(H)$. Ca currents were activated by $100 \mathrm{msec}$ pulses to $+20 \mathrm{mV}$ from a holding voltage of $-40 \mathrm{mV}$ and scaled by membrane area. $B$, Same 3 patch currents scaled to the peak amplitude of the whole-cell current and plotted with the whole-cell current. The patch current at $H$ overlaps the current in the whole cell. $C$, Patch currents of equal density recorded at 2 locations. The Ca current at $45^{\circ}$ $\mathrm{S}(H)$ was activated by a pulse to $-10 \mathrm{mV}$, and the current at the soma cap $(C)$ was activated by a pulse to $+20 \mathrm{mV}$. The holding voltage was $-40 \mathrm{mV} . D$, Ba currents recorded in the whole cell and in 2 patches located at the equator $(E)$ and at $45^{\circ} \mathrm{S}(H)$. The patch currents were scaled to the peak amplitude of the whole-cell current, and the current at $H$ overlaps the whole-cell current. The same patch pipette was used throughout. Filter corner frequency, $1 \mathrm{kHz}$.

nearer the hillock (Fig. 2, $F$ and $G$ ), but the current in Figure $2 A$ does not inactivate. This result is important because it shows that currents at the soma cap and nearer the hillock behave differently during the same depolarizing pulse even when the peak current density and the number of active channels is approximately the same at both locations. We conclude that the strength of $\mathrm{Ca}$ current inactivation is not determined solely by the amplitude of the local $\mathrm{Ca}$ influx or the local channel density. Instead, inactivation is related to position on the cell body and determined by some feature of the cell that is distributed in a spatial gradient.

The inward current in molluscan neurons inactivates more slowly and less completely when $\mathrm{Ba}$ is substituted for $\mathrm{Ca}$, and it is thought that while Ba can traverse the channel, it is less effective than Ca in causing inactivation (Tillotson, 1979; Eckert and Tillotson, 1981; see Eckert and Chad, 1984). Figure $4 D$ shows inward currents during $100 \mathrm{msec}$ pulses to $+20 \mathrm{mV}$ after substituting $\mathrm{Ba}$ for $\mathrm{Ca}$ in both the bathing medium and the patch pipette. The whole-cell current and currents from 2 patches located at the equator $(\mathrm{E})$ and $45^{\circ} \mathrm{S}(\mathrm{H})$ are shown scaled to the peak amplitude of the whole cell current. Ba currents are larger than Ca currents recorded at the same locations and, as in other molluscan neurons, they inactivate very little. If it is assumed that $\mathrm{Ba}$ does not substitute for $\mathrm{Ca}$ in causing inactivation and that external $\mathrm{Ba}$ and $\mathrm{Ca}$ have equal access to the membrane, the results of this experiment indicate that local differences in extracellular ion depletion cannot account for the variability in inactivation.
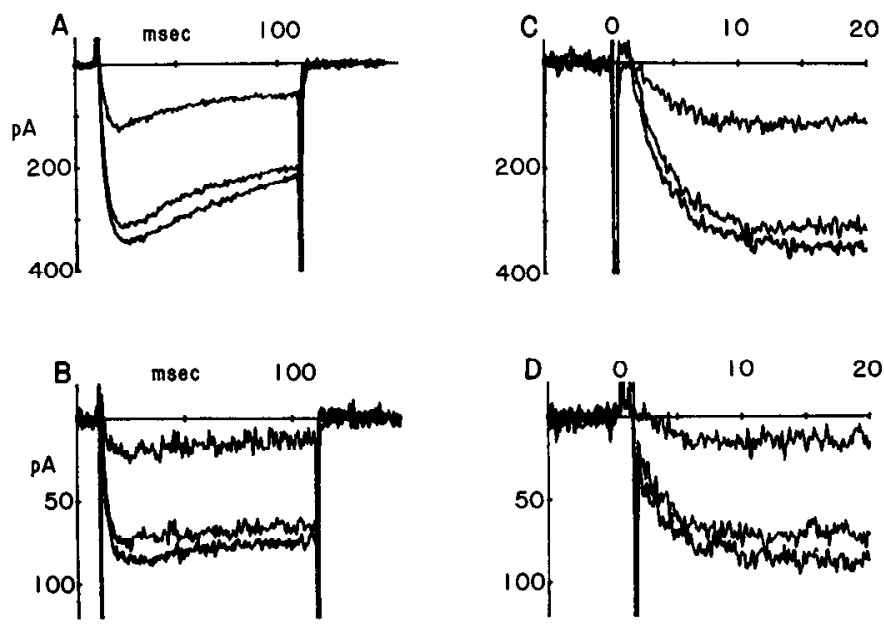

Figure 5. Time course of $\mathrm{Ca}$ current activation. Ca currents were recorded from 2 patches on the same cell during $100 \mathrm{msec}$ pulses to 0 , +20 , and $+40 \mathrm{mV}$ from a holding voltage of $-40 \mathrm{mV}$. $A$, Ca currents in a patch near the equator that showed strong inactivation. $B, \mathrm{Ca}$ currents at the soma cap that inactivate weakly during depolarization. The currents are replotted on an expanded time base in $C$ and $D$ to illustrate the similarity in activation time course. Filter corner frequency, $2 \mathrm{kHz}$.

We can think of 2 possible explanations for the differences we observed in the strength of Ca current inactivation: (1) The cells might express 2 types of $\mathrm{Ca}$ channels with different inactivation properties and different patterns of spatial distribution on the neuronal surface, or (2) there may be only one type of channel, but a factor that is necessary for inactivation, or a factor that influences the sensitivity of inactivation to internal $\mathrm{Ca}$, may be unevenly distributed. The kinetics and voltage dependence of inactivating and noninactivating $\mathrm{Ca}$ currents were studied in detail in an attempt to distinguish between these possibilities.

\section{Kinetics of Ca current activation}

$\mathrm{Ca}$ currents at different locations activate at approximately the same rate regardless of the degree of inactivation that occurs during depolarization. Figure 5 shows Ca currents recorded from 2 patches located near the equator and near the soma cap of the same cell during $100 \mathrm{msec}$ pulses to $0,+20$, and $+40 \mathrm{mV}$. Ca currents near the equator inactivate by about $20 \%$ during each pulse, while the currents at the soma cap inactivate very little. The expanded records in Figure 5, $C$ and $D$, show that the time course of $\mathrm{Ca}$ current activation is approximately the same at both locations. For 20 strongly inactivating patch currents, the average half-rise time was $3.9+1.2(\mathrm{SD}) \mathrm{msec}$, and the average time-to-peak was $15+1.2 \mathrm{msec}$. In 20 patches in which the current did not inactivate, the half-rise time was $4.3+0.9 \mathrm{msec}$ and the time to peak was $18+5.6 \mathrm{msec}$. Inactivating and noninactivating currents could not be distinguished on the basis of activation kinetics.

\section{Ca tail currents}

The time course of the Ca tail current on repolarization is similar for inactivating and noninactivating $\mathrm{Ca}$ currents. Figure $6 \mathrm{~A}$ shows $\mathrm{Ca}$ currents recorded in patches at the soma cap (C) and at $45^{\circ}$ $\mathrm{S}(\mathrm{H})$ during a $500 \mathrm{msec}$ pulse to $+20 \mathrm{mV}$. The current at $\mathrm{H}$ inactivates more strongly than the current at the cap. Figure $6 B$ shows $\mathrm{Ca}$ tail currents on returning to $-40 \mathrm{mV}$ after a $10 \mathrm{msec}$ pulse to $+20 \mathrm{mV}$ in the same membrane patches. The tail 
A
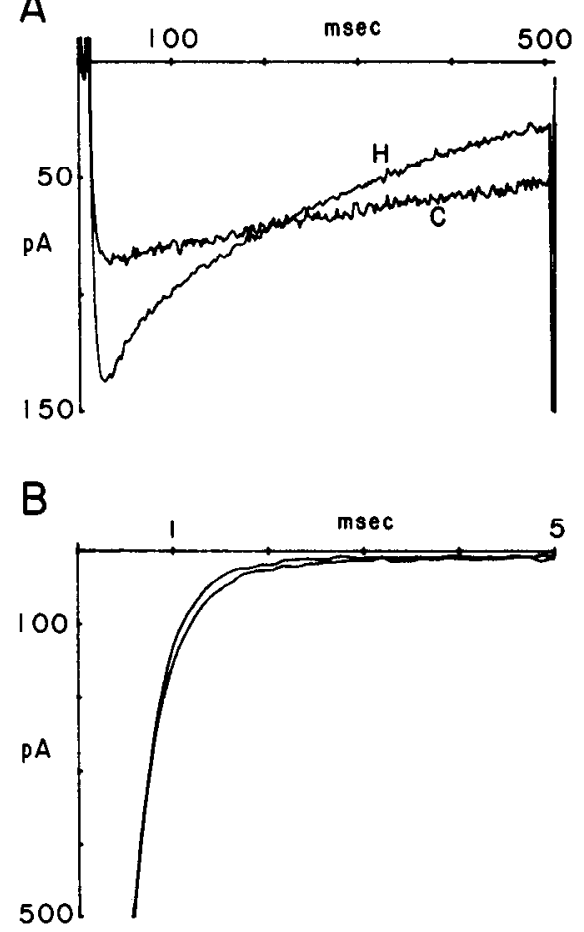

Figure 6. Ca tail currents. A, Ca currents during $500 \mathrm{msec}$ depolarizations to $+20 \mathrm{mV}$ in 2 patches from the same cell. The current near the axon hillock $(H)$ showed strong inactivation, while the patch current at the soma cap $(C)$ inactivated weakly. $B, C a$ tail currents on returning to $-40 \mathrm{mV}$ after a $10 \mathrm{msec}$ pulse to $+20 \mathrm{mV}$ in the same 2 membrane patches. The tail currents were scaled to the amplitude $0.6 \mathrm{msec}$ after repolarization and plotted from this time on. Filter corner frequency, $2 \mathrm{kHz}$.

currents were vertically scaled to the amplitude $0.6 \mathrm{msec}$ after repolarization and plotted from this time on. Tail currents in the 2 patches follow identical time courses and are well fit by a single exponential with a time constant of $0.8 \mathrm{msec}$. Similar results were obtained over a wide range of activating voltages, pulse durations, and repolarization voltages in 5 experiments.

In 3 experiments, Ca tail currents were recorded in 2 salines that differed in $\mathrm{K}$ concentration. Tail currents were recorded on repolarization to $-40 \mathrm{mV}$ after a $50 \mathrm{msec}$ pulse to $+20 \mathrm{mV}$ first in $10 \mathrm{~mm} \mathrm{~K}$ saline and again after changing the solution in the bath and in the patch pipette to one containing $40 \mathrm{~mm} \mathrm{~K}$. In each experiment the amplitude and time course of the tail current were insensitive to the external $\mathrm{K}$ concentration, showing that $\mathrm{Ca}$ currents are successfully separated from $\mathrm{K}$ currents under the conditions of this study.

\section{Voltage dependence of Ca current activation}

The voltage dependence of Ca current activation was estimated in 2 ways. In the first procedure, a series of $500 \mathrm{msec}$ depolarizing pulses was applied from a holding voltage of $-70 \mathrm{mV}$. The inactivating phase of the current during each pulse was fit by the sum of 2 exponentials, and the maximum amplitude of the current was estimated by summing the $y$-intercepts of the fitted curves with the steady-state current at the end of the pulse. Maximum current amplitude was plotted against pulse voltage to produce an $I(V)$ curve. Three $I(V)$ curves from a single neuron are shown in Figure $7 \mathrm{~A}$. They represent the whole-cell current, the current in a patch near the axon hillock that inactivated
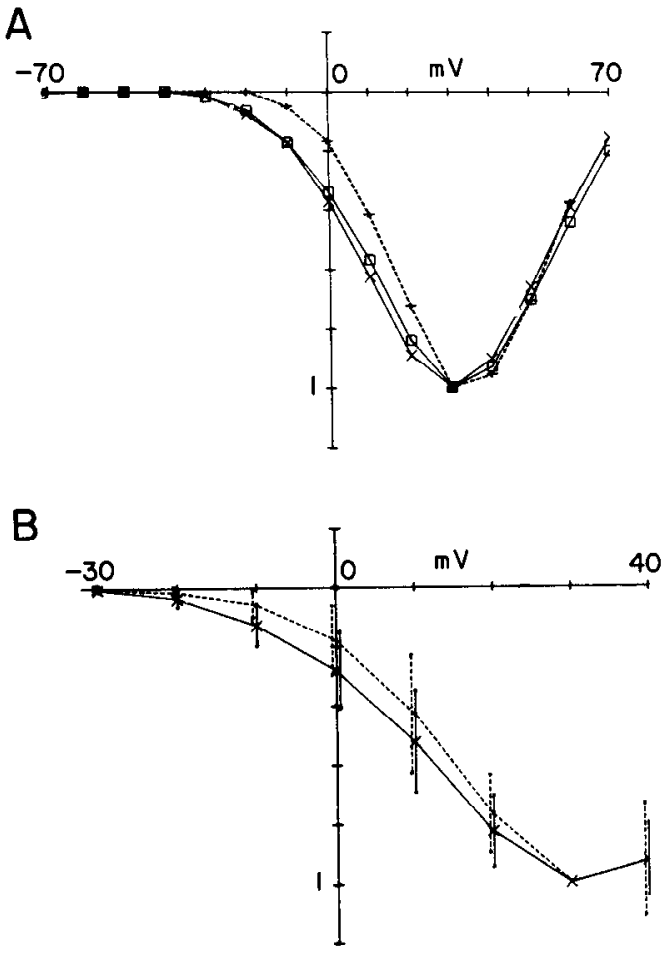

Figure 7. Voltage dependence of Ca current activation. $A, I(V)$ curves for whole-cell current $(x)$, patch current near the axon hillock that showed strong inactivation ( $\square$ ), and patch current near the soma cap did not inactivate during depolarization $(\cdots)$. The maximum $\mathrm{Ca}$ current amplitude is plotted against pulse voltage for a series of $500 \mathrm{msec}$ pulses from -70 to $+70 \mathrm{mV}$. Maximum amplitude was determined by fitting the inactivating phase of the current by the sum of 2 exponentials and summing the $y$-intercepts of the fitted curves with the steady current at the end of the pulse. The $3 I(V)$ curves were normalized to the maximum amplitude during a pulse at $+30 \mathrm{mV}$. All 3 curves are from the same neuron. $B$, Averaged $I(V)$ curves for 14 patches that showed strong Ca current inactivation $(-$ ) and 33 patches that showed no inactivation $(\cdots)$. The points on the curves show the average peak current amplitude at each voltage normalized to the peak amplitude during a pulse to $+30 \mathrm{mV}$. The vertical bars represent $\pm 1 \mathrm{SD}$.

strongly, and the current in a patch near the soma cap that did not inactivate during depolarization. The $I(V)$ curves were normalized to the maximum current during a pulse to $+30 \mathrm{mV}$ for comparison. In each case the $I(V)$ curve shows no indication of separate, overlapping ranges of activation that would suggest the presence of more than one type of Ca current. The $I(V)$ curves for the whole-cell current and the strongly inactivating patch current are nearly identical; Ca current is first seen with depolarization to $-30 \mathrm{mV}$, and the current reaches a maximum with a pulse to $+30 \mathrm{mV}$. The $I(V)$ curve for noninactivating $\mathrm{Ca}$ current is shifted toward the right. This was a consistent finding; in the majority of experiments the foot of the $I(V)$ curve for noninactivating current was $5-15 \mathrm{mV}$ to the right of the curve for strongly inactivating current in the same cell.

$I(V)$ curves were also constructed from the peak amplitudes of Ca currents recorded during a series of depolarizing test pulses. The peak currents were normalized to the current during a pulse to $+30 \mathrm{mV}$ and plotted against test pulse voltage. Figure $7 B$ shows the average $I(V)$ curve for 14 patches in which the $\mathrm{Ca}$ current inactivated strongly and for 33 patches in which the current did not inactivate. On average, the noninactivating $\mathrm{Ca}$ current begins to activate at a somewhat more depolarized voltage than the strongly inactivating current. There was consid- 

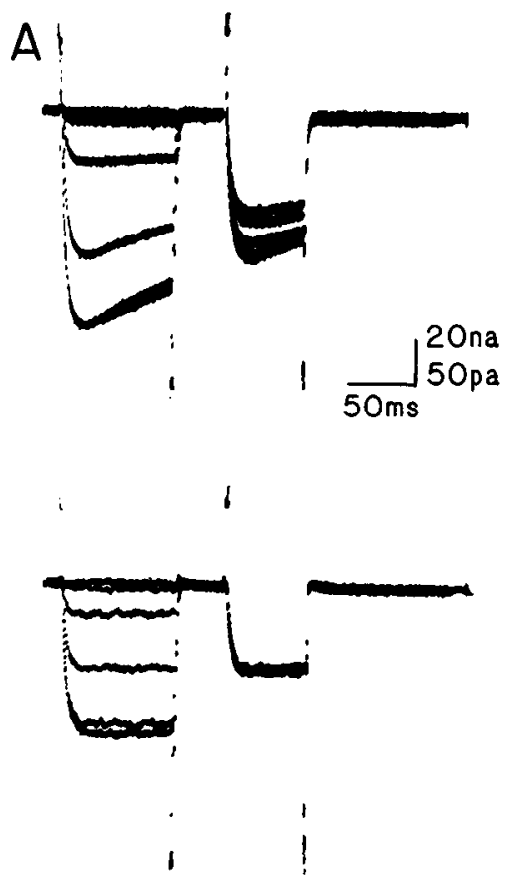

B
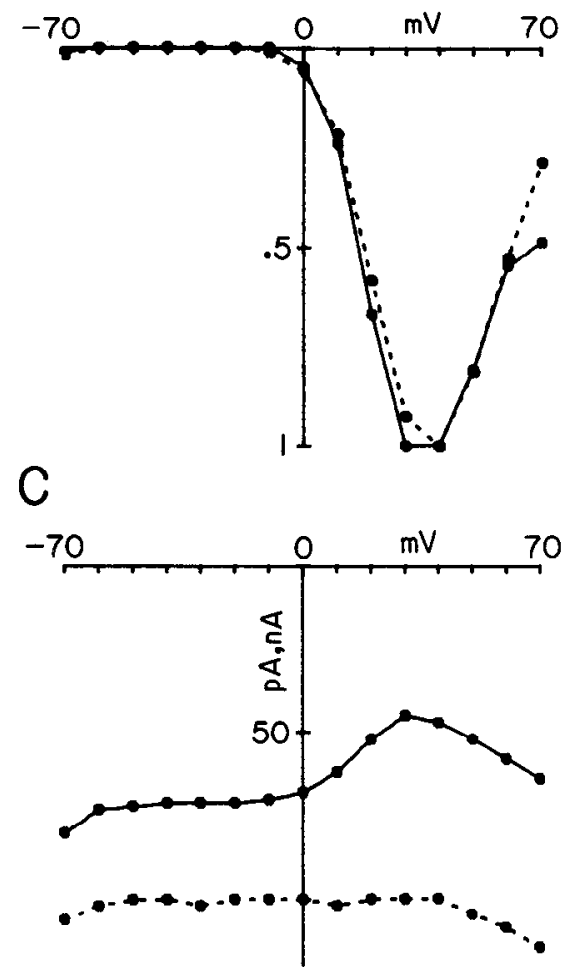

Figure 8. Prepulse inactivation. $A$, Sample records showing membrane currents during a series of $100 \mathrm{msec}$ prepulses to voltages between -20 and $+30 \mathrm{mV}$ in $10 \mathrm{mV}$ increments followed, after a $30 \mathrm{msec}$ delay, by a 100 msec test pulse to $+20 \mathrm{mV}$. Upper records show Ca currents in the whole cell; lower records, currents in a patch located at the soma cap. Filter corner frequency, $1 \mathrm{kHz} . B, I(V)$ curves showing the peak amplitudes of whole cell (-) and patch $\mathrm{Ca}$ currents $(\cdots)$ ) plotted against the prepulse voltage for prepulses between -70 and $+70 \mathrm{mV}$. The $I(V)$ curves were normalized to the peak amplitude during a pulse to $+30 \mathrm{mV}$. $C$, $I(V)$ curves showing the peak amplitudes of test currents plotted against prepulse voltage in the whole cell (in $\mathrm{nA} ;-$ ) and in the patch (in $\mathrm{pA}$; $(\cdots$.$) . All records are from the same$ neuron. erable variability between patches, however, as shown by the large SDs, and, in some experiments, the $I(V)$ curves for inactivating and noninactivating currents were identical. The difference between the averaged $I(V)$ curves could have resulted from an artifact of the measurement procedure. This point is treated in the Discussion.

\section{Prepulse inactivation of Ca current}

The effects of conditioning voltage steps on Ca current inactivation were studied using the prepulse protocol suggested by Tillotson (1979), and the results of such an experiment are shown in Figure 8 . The cell was held at $-40 \mathrm{mV}$, and $100 \mathrm{msec}$ prepulses to voltages between -70 and $+70 \mathrm{mV}$ were applied. At the end of the prepulse, the voltage was returned to $-40 \mathrm{mV}$ for $30 \mathrm{msec}$ before applying a $100 \mathrm{msec}$ test pulse to $+20 \mathrm{mV}$. Figure $8 A$ shows example records of whole-cell $\mathrm{Ca}$ currents and currents in a patch at the soma cap, and Figure $8 B$ shows the pair of $I(V)$ curves that results from plotting the peak amplitude of the whole-cell current and patch current during the prepulses against prepulse voltage. The $I(V)$ curves were normalized to the peak amplitude of the current during a pulse to $+30 \mathrm{mV}$. In this example, the whole-cell current and the patch current activate with the same voltage dependence.

Figure $8 C$ shows the $I(V)$ curves that result from plotting the peak amplitudes of the whole-cell currents and patch currents during the test pulses against prepulse voltage. In the whole cell, prepulses to between 0 and $+30 \mathrm{mV}$ cause increasing inactivation of the test current, and the current amplitude recovers with still larger prepulses. The shape of this $I(V)$ curve is approximately the inverse of the curves in Figure $8 B$ : Inactivation reaches a maximum at the voltage where the prepulse $\mathrm{Ca}$ current is maximal. The Ca current in the patch, on the other hand, is not affected by prepulses in this voltage range, showing that $\mathrm{Ca}$ current near the soma cap that does not inactivate during depolarization is also immune to prepulse inactivation.

The effect of holding potential on Ca current was studied in 10 experiments in an attempt to separate individual components of the current on the basis of differences in the voltage dependence of steady-state inactivation. Test pulses to voltages between -30 and $+70 \mathrm{mV}$ were applied from 2 holding voltages, -40 and $-100 \mathrm{mV}$, and recordings were made from patches at different locations. Holding voltage had no effect on the amplitude or waveform of the Ca current or on the $I(V)$ curve, regardless of the strength of inactivation during depolarization.

\section{Intracellular Ca injection}

Ca currents recorded near the soma cap that do not inactivate during depolarization are reduced by intracellular $\mathrm{Ca}$ injection. Ca was injected iontophoretically into the cortical cytoplasm from a microelectrode positioned just under the patch pipette. Ca currents were recorded from the patch and from the whole cell during $100 \mathrm{msec}$ test pulses to $+20 \mathrm{mV}$ presented at $1 \mathrm{~min}$ intervals before, during, and after injection. The 2 upper traces in Figure 9 show chart records of the iontophoretic current and the whole-cell Ca current on the same time base; the lower pairs of traces show the patch and whole-cell currents during the same pulses on an expanded time scale. The patch current before injection does not inactivate during depolarization. An iontophoretic pulse was applied to injected a total of $3.6 \mathrm{pmol} \mathrm{Ca}$ into the cytoplasm near the membrane under the patch pipette. $\mathrm{Ca}$ injection reduced the amplitude of the patch current by onehalf but had little effect on the whole-cell current. Patch current recovered to the control amplitude within $2.5 \mathrm{~min}$ after injection. Similar results were obtained in 5 experiments. They show 

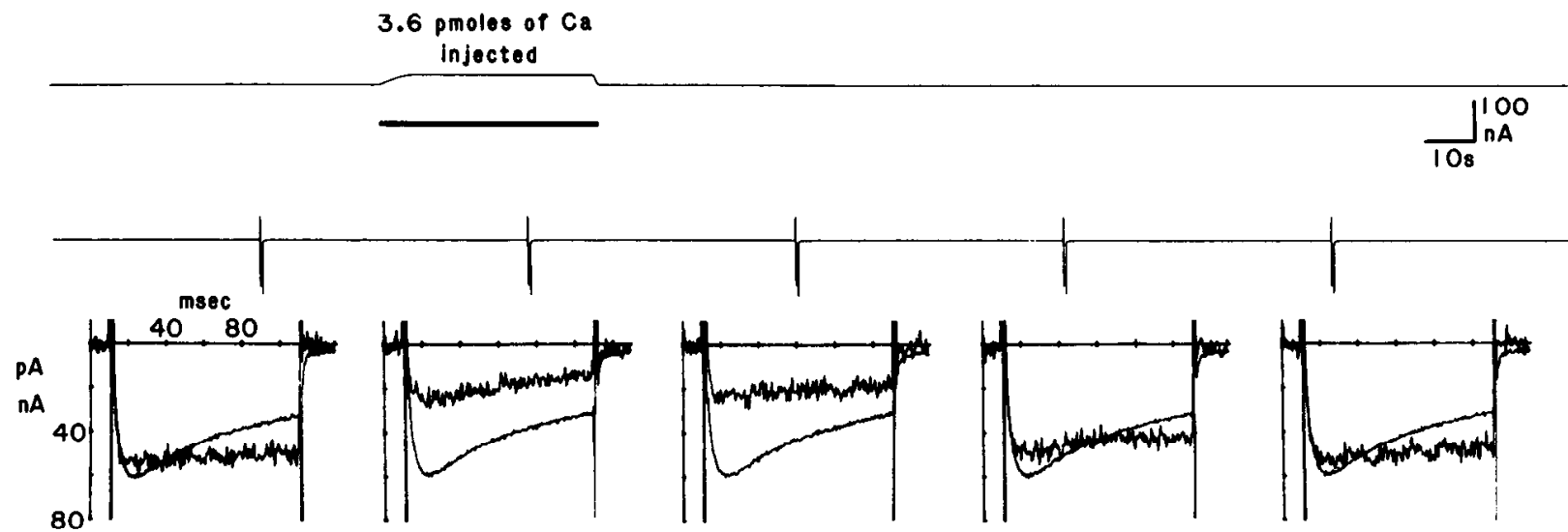

Figure 9. Ca injection reduces noninactivating Ca current. Ca currents were activated by $100 \mathrm{msec}$ pulses to $+20 \mathrm{mV}$ presented at $1 \mathrm{~min}$ intervals from a holding voltage of $-40 \mathrm{mV}$. Currents were recorded simultaneously from the whole cell and from a patch at the soma cap. An iontophoretic microelectrode containing $0.5 \mathrm{M} \mathrm{CaCl}_{2}$ was introduced into the cortical cytoplasm directly under the patch pipette. Uppermost trace shows a continuous chart record of the iontophoretic current; middle trace, whole-cell Ca current on the same time base; lower pairs of records, whole-cell currents (in $\mathrm{nA}$ ) and patch currents (in pA) before, during, and after injection on an expanded time scale. Filter corner frequency, $1 \mathrm{kHz}$.

that Ca current near the soma cap is subject to Ca-dependent inactivation and that $\mathrm{Ca}$ has access to that mechanism, even though the current does not inactivate during depolarization.

In Figure 9, $\mathrm{Ca}$ injection had little effect on the whole-cell $\mathrm{Ca}$ current. With the same electrode placement, a significant reduction in whole-cell current could be obtained by incrcasing the amplitude or duration of the iontophoretic pulse. During large $\mathrm{Ca}$ injections, however, the leakage current of the patch near the iontophoretic electrode usually increased. This occurred locally and was not readily apparent in the whole-cell current record. Also, after large Ca injections the cell often responded by producing membrane blebs near the site of injection, indicating a catastrophic change in the integrity of the cortical cytoskeleton. Increased leakage current and the formation of
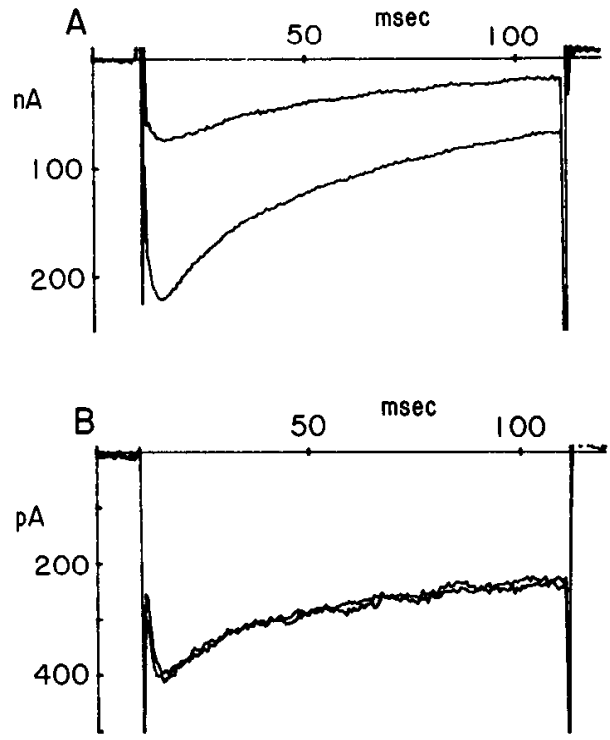

Figure 10. Ca currents recorded simultaneously from the whole cell $(A)$ and from a patch near the equator $(B)$ during $100 \mathrm{msec}$ pulses to $+20 \mathrm{mV}$. Currents were recorded first in normal saline and then during focal perfusion of the membrane outside of the patch with $\mathrm{Ca}$-free, $\mathrm{Mn}$ saline. Focal perfusion with $\mathrm{Mn}$ saline reduced the amplitude of the whole-cell current by two-thirds but had no effect on the patch current. Filter corner frequency, $1 \mathrm{kHz}$. blebs were not seen with small injections like that illustrated in Figure 9 that were sufficient to reduce the amplitude of the local Ca current.

The $\mathrm{Ca}$ injection experiments provide an important control for the possible contamination of $\mathrm{Ca}$ current by $\mathrm{Ca}$-dependent $\mathrm{K}$ current. In each of 10 experiments, $\mathrm{Ca}$ injection did not activate outward current in the patch or whole cell at the -40 $\mathrm{mV}$ holding potential or during depolarizing pulses, showing that $\mathrm{Ca}$-dependent $\mathrm{K}$ current is successfully blocked.

\section{Cyloplasmic $C$ a concentration change remains localized}

Ca current inactivation depends on the local change in cytoplasmic Ca concentration near the patch rather than the average concentration change in the cell body. This was shown by recording Ca currents from a patch near the equator that showed moderate inactivation. The solution bathing the area surrounding the patch was changed from normal saline to a Ca-free, $\mathrm{Mn}$ saline using a focal perfusion method (Thompson et al., 1986). The perfusion stream directed the Mn saline over about half of the cell body and was centered on the point where the patch pipette was attached. The saline in the pipette was not changed. Because $\mathrm{Mn}$ is not permeable in Ca channels, Ca current in the surrounding membrane is eliminated during the perfusion and the local $\mathrm{Ca}$ influx is restricted to the membrane within the patch pipette. Since the stream of Mn saline is applied focally, $\mathrm{Ca}$ current will still occur in soma membrane far away from the patch. Figure 10, $A$ and $B$, shows whole-cell currents and patch currents in $\mathrm{Ca}$ saline and during perfusion with $\mathrm{Mn}$ saline. The whole-cell Ca current is reduccd by two-thirds during focal pcrfusion, but the remaining current inactivates at the same rate as the control. The amplitude and time course of the patch current remain unchanged. These findings show that $\mathrm{Ca}$ entering through adjacent membrane has little influence on the inactivation of $\mathrm{Ca}$ current in the patch and that the $\mathrm{Ca}$ concentration change remains localized to the vicinity of the patch during pulses of this duration.

\section{Discussion}

\section{Spatial distribution of Ca current}

There have been several reports describing the localization of inward currents in molluscan neurons. Kado (1973) used a pair of differential electrodes to record local currents from the soma 
of Aplysia neuron R2 and found that TTX-sensitive inward current was relatively larger near the emergence of the axon, whereas TTX-insensitive current (probably Ca current) was relatively larger at the soma cap. Scheffey (1975) used the vibratingprobe method to record local currents in Helix neurons and scaled the currents by membrane capacitance in order to compare current densities in different regions. He confirmed Kado's finding that the $\mathrm{Na}$ current is largest near the axon hillock and showed that $\mathrm{Ca}$ currents can be recorded over the entire surface of the cell body. Horn (1978) found that the axon of Aplysia neuron R2 can support $\mathrm{Ca}$ action potentials up to $1 \mathrm{~cm}$ from the cell body, indicating that $\mathrm{Ca}$ channels are widely distributed and not restricted to the soma. The high spatial resolution of the large patch method made it possible to study the distribution of Ca current on a finer spatial scale.

$\mathrm{Ca}$ current is not evenly distributed in the cell body. Analysis of the data from many patches indicates that there is a moderately steep gradient of increasing current density from the soma cap to the axon hillock, and there appears to be a sharp increase in current density just below the equator. The $\mathrm{Ca}$ current density in each region is highly variable, and in each region there are patches that have an unusually high current density that represent current "hot spots." This suggests that Ca channels may occur in macroscopic clusters involving a few hundred channels. The gradient in current density could result from increasingly close spacing of channel clusters as the axon hillock is approached.

The cellular processes that govern the distribution of Ca channels are not known, but the particular relationship between glial cells and neurons in molluscs suggests the possibility that glial cells may influence $\mathrm{Ca}$ channel localization. Glial cells invaginate the soma and cause infolding of the surface membrane (Mirolli and Talbot, 1972; Mirolli and Gorman, 1973). Infolding is common near the axon hillock but rare or absent near the soma cap, and, therefore, the distribution of glial processes roughly parallels the distribution of Ca current. It is possible that glialneuronal interactions play a role in establishing the Ca channel distribution by affecting the structure of the neuronal cortical cytoplasm or the anchoring of Ca channels. A similar hypothesis has been suggested to explain the localization of $\mathrm{Na}$ channels at nodes of Ranvier in vertebrate axons (Poo, 1985; Waxman and Ritchie, 1985).

\section{Are there two types of Ca currents?}

One of the principle criteria used to distinguish between different types of $\mathrm{Ca}$ currents is the strength of inactivation during depolarization (Eckert and Chad, 1984; McCleskey et al., 1986; Miller, 1987). A possible explanation for the data presented here is that these neurons express 2 types of Ca currents with different preferred distributions such that the more strongly inactivating current tends to occur nearer the axon hillock. A number of experiments were performed in an attempt to separate the $\mathrm{Ca}$ current into 2 or more components.

In vertebrate neurons, inactivating and noninactivating $\mathrm{Ca}$ currents can sometimes be separated because of differences in the voltage dependence of activation (Tsien, 1983; Miller, 1987). In the present experiments, noninactivating $\mathrm{Ca}$ current begins to activate at a slightly more depolarized voltage than strongly inactivating current. The difference is much less than that characterizing $\mathrm{L}$ and $\mathrm{T}$ channel activation or type $\mathrm{I}$ and type II currents in vertebrate neurons and invertebrate eggs (Hagiwara et al., 1975; Carbone and Lux, 1984a, b; Nowycky et al., 1985;
Narahashi et al., 1987). It appears that if 2 kinds of Ca currents are expressed in the molluscan cells, they do not correspond to the high- and low-threshold $\mathrm{Ca}$ currents in other preparations.

The differences between the $I(V)$ curves for inactivating and noninactivating $\mathrm{Ca}$ current could result from an artifact of the measurement procedure rather than a real difference in the currents. The interpretation of $I(V)$ curves requires that a particular model be assumed for the mechanisms of activation and inactivation. Implicit in the way we treated the data is the assumption that these processes are independent, but this cannot be strictly correct since the strength of inactivation is known to depend on current amplitude (see Eckert and Chad, 1984). The $I(V)$ curves in Figure 8 were constructed in 2 ways: either by measuring the peak current during depolarizing pulses or by extrapolating the decline in current during depolarization back to the beginning of the pulse. The data were normalized to the maximum current to allow comparison of $I(V)$ curves measured at different locations. If activation and inactivation are not independent, both methods for plotting the $I(V)$ curve could underestimate the maximum amplitude of an inactivating current. Normalization could then produce an apparent difference in the $I(V)$ curves for inactivating and noninactivating currents, especially for smaller pulses, that could account for the results illustrated in Figure 7. Because of this consideration, and the fact that in some experiments the $I(V)$ curves for inactivating and noninactivating current were identical (see Fig. 8), we do not think that the $I(V)$ curves provide convincing evidence for 2 types of $\mathrm{Ca}$ currents.

Inactivating and noninactivating $\mathrm{Ca}$ currents share other characteristics. They cannot be distinguished on the basis of their sensitivity to hyperpolarizing conditioning pulses or changes in holding potential, or by differences in the kinetics of activation or deactivation, criteria that were important for separating different types of Ca currents in invertebrate oocytes and vertebrate neurons (Hagiwara et al., 1975; Carbone and Lux, 1984a, b; Armstrong and Matteson, 1985; Nowycky et al., 1985; Matteson and Armstrong, 1986; McCleskey et al., 1986; Narahashi et al., 1987). Ca current near the soma cap that does not inactivate during depolarization is reduced by intracellular $\mathrm{Ca}$ injection and, therefore, appears to be sensitive to Ca-dependent inactivation. The Ca injection procedure cannot be used to determine if inactivation is equally sensitive to internal $\mathrm{Ca}$ at all locations. This is because the local concentration change depends strongly on the placement of the injection electrode. Ca diffuses slowly in cytoplasm, and while it is expected that the concentration change will remain localized for a short time after injection, the volume that receives the $\mathrm{Ca}$ load and the local buffer strength are not known. This prevents us from calculating the local concentration change during injection and makes it inappropriate to attempt a quantitative comparison of the sensitivity of $\mathrm{Ca}$ current inactivation to injected $\mathrm{Ca}$ at different locations.

The simplest interpretation of the data is that the somatic $\mathrm{Ca}$ current in these cells involves only one type of $\mathrm{Ca}$ channel. A definitive test of this idea will require single-channel recording of $\mathrm{Ca}$ currents at different locations. Lux and Brown (1984) recorded single-channel $\mathrm{Ca}$ currents in Helix neurons and reported that the ensemble average of single-channel currents had the same inaclivating waveform as the whole-cell current. They did not find evidence for more than one type of $\mathrm{Ca}$ channel, but they did not report the locations of the patches. Chesnoy-Marchais (1985) described 2 kinds of Ca channels in Aplysia neurons in high-Na saline. Only one of these was similar in voltage 
dependence to the current we recorded in the cell body. The other, smaller conductance channel activated at more negative voltages and may correspond to the noninactivating Ca current observed in certain pacemaker neurons in molluscs (Gola, 1974; Eckert and Lux, 1976; Adams and Levitan, 1985; Kramer and Zucker, 1985; Smith and Thompson, 1987). This current was not seen in the present experiments.

If it is assumed that the cell expresses only one type of $\mathrm{Ca}$ channel with uniform properties, then how can the variability in the strength of inactivation be explained? One important finding in this study is that the strength of inactivation varies between patches even when the current density and, according to the assumption, the number of active $\mathrm{Ca}$ channels and the single-channel current are the same. This shows that differences in the strength of inactivation are not explainable by differences in local current density. One possible explanation is that there may be local differences in the strength of the cytoplasmic $\mathrm{Ca}$ buffer. Figure 10 showed that the local Ca concentration change, rather than the average concentration change in the soma, is the important factor determining the strength of inactivation. If the cytoplasmic Ca concentration is buffered more strongly at the soma cap, or if diffusion away from the membrane is relatively unrestricted in that region, the local $\mathrm{Ca}$ concentration change during depolarization might not reach the level required to cause inactivation. Less effective buffering near the hillock or a morc highly compartmentalized cytoplasm in that region might allow $\mathrm{Ca}$ to accumulate more readily and reach a higher local concentration. It has been suggested that cellular Ca buffering is not uniform in the radial dimension; the cortical cytoplasm is thought to buffer Ca more strongly than the more central cytoplasm (Tillotson and Gorman, 1980; Barish and Thompson, 1983). The buffer strength might be nonuniform around the circumference of the cell as well, with more efficient buffering occurring near the soma cap. This could occur, for example, if $\mathrm{Ca}$ active transport sites are concentrated near the cap. Also, glial infoldings near the axon hillock might create restricted intracellular compartments between invaginating processes where $\mathrm{Ca}$ could readily accumulate. According to these ideas, the strength of inactivation does not depend on the properties of the $\mathrm{Ca}$ channel, but on regional differences in cellular morphology or in the distribution of $\mathrm{Ca}$ active transport sites and cytoplasmic buffers.

Local differences in the strength of inactivation could also occur if a cytoplasmic factor or enzyme that is necessary for inactivation is unevenly distributed. This would be consistent with the work of Brown et al. (1984) showing that Ca inactivation has a high temperature dependence suggestive of a metabolic step in the inactivation process (see Brown et al., 1986). Chad and Eckert (1986) found that the rate of Ca inactivation is increased when Helix neurons are dialyzed with a Ca-dependent phosphatase, calcineurin. They proposed a model in which inactivation results from dephosphorylation of the channel due to increased activity of an endogenous Ca-dependent phosphatase. Regional differences in the strength and rate of inactivation could be explained by nonuniform distribution of membranebound phosphatase in the soma. Alternatively, Ca channels at certain locations could be modified enzymatically to change the sensitivity of inactivation to internal $\mathrm{Ca}$ after the channels are inserted into the membrane. Experiments on Paramecium provide a precedent for these ideas. In certain mutants of Paramecium, Ca currents exhibit reduced Ca-dependent inactivation relative to wild-type strains (Hinrichson and Saimi, 1984). The mutant apparently lacks a factor necessary for inactivation because of an altered channel structure or a change in a necessary metabolic step.

The data presented in this paper show that qualitative differences in the strength of Ca current inactivation occur between patches and raise the possibility that the same type of Ca channel can perform differently depending on its location in the soma membrane. The present models for $\mathrm{Ca}$-dependent inactivation that are based on whole-cell voltage-clamp experiments should be reconsidered. It is apparent that a fraction of the Ca current in the soma does not inactivate during depolarization, that the strength of inactivation shows a high degree of spatial variability, and that the whole-cell $\mathrm{Ca}$ current is the weighted sum of inactivating and noninactivating currents. Also, classification of $\mathrm{Ca}$ currents on the basis of differences in the strength of inactivation may be inappropriate because inactivation may involve features of the cell that are not associated with the Ca channel protein.

\section{Significance of local differences in Ca current}

The somatic $\mathrm{Ca}$ current influences the excitability and repetitive firing properties of the neuron by contributing inward current during spike initiation. The spatial gradient in Ca current distribution in the soma is not expected to have a direct effect on this integrative process because the cell body is nearly isopotential during normal activity. However, the presence of noninactivating $\mathrm{Ca}$ current in the soma may have important consequences for neuronal function. $\mathrm{Ca}$ ions act as cytoplasmic second messengers with a wide range of effects - influencing the activation of $\mathrm{Ca}$-dependent currents, synaptic transmission from nearby axodendritic synapses, and the activity of Ca-dependent enzymes. The spatial gradient in $\mathrm{Ca}$ current density, regional differences in the strength of inactivation, and the fact that the intracellular $\mathrm{Ca}$ concentration change remains localized mean that different regions of the soma receive different Ca signals during normal activity, which produces a temporal compartmentalization of the $\mathrm{Ca}$ signal.

\section{References}

Adams, W. B., and I. B. Levitan (1985) Voltage and ion dependences of the slow currents which mediate bursting in Aplysia neurone R15. J. Physiol. (Lond.) 260: 69-93.

Armstrong, C. M., and D. R. Matteson (1985) Two distinct populations of calcium channels in a clonal line of pituitary cells. Science 227: 65-67.

Barish, M. E., and S. H. Thompson (1983) Calcium buffering and slow recovery kinetics of calcium-dependent outward current in molluscan neurones. J. Physiol. (Lond.) 337: 201-219.

Bean, B. P. (1985) Two kinds of calcium channels in canine atrial cells. Differences in kinetics, selectivity and pharmacology. J. Gen. Physiol. 86: 1-30.

Brown, A. M., H. D. Lux, and D. L. Wilson (1984) Activation and inactivation of single calcium channels in snail neurons. J. Gen. Physiol. 83: 751-769.

Brown, A. M., D. L. Kunze, and H. D. Lux (1986) Single calcium channels and their inactivation. Membr. Biochem. 6: 73-81.

Byerly, L., and S. Hagiwara (1982) Calcium currents in internally perfused nerve cell bodies of Limnaea stagnalis. J. Physiol. (Lond.) 322: 503-528

Carbone, E., and H. D. Lux (1984a) A low voltage-activated, fully inactivating $\mathrm{Ca}$ channel in vertebrate sensory neurons. Nature 310 : 501-502.

Carbone, E., and H. D. Lux (1984b) A low voltage-activated calcium conductance in embryonic chick sensory neurons. Biophys. J. 46:413418.

Chad, J. E., and R. Eckert (1986) An enzymatic mechanism for calcium 
current inactivation in dialysed Helix neurones. J. Physio. (Lond.) 378: $31-51$.

Chesnoy-Marchais, D. (1985) Kinetic properties and selectivity of calcium-permeable single channels in Aplysia neurones. J. Physiol. (Lond.) 367: 457-488.

Eckert, R., and J. E. Chad (1984) Inactivation of Ca channels. Prog. Biophys. Mol. Biol. 44: 215-267.

Eckert, R., and H. D. Lux (1976) A voltage-sensitive persistent calcium conductance in neuronal somata of Helix. J. Physiol. (Lond.) 254: 129-151.

Eckert, R., and D. Tillotson (1981) Calcium-mediated inactivation of the calcium conductance in caesium-loaded giant neurones of Aplysia californica. J. Physiol. (Lond.) 314: 265-280.

Frank, K., and I. Tauc (1963) Voltage-clamp studies of molluscan neuron membrane properties. In The Cellular Function of Membrane Transport, J. Hoffman, ed., pp. 113-135, Prentice-Hall, Englewood Cliffs, NJ.

Gola, M. (1974) Neurons a ondes-salves des mollusques, variations cycliques lentes des conductances ioniques. Pfluegers Arch. 352: 1736.

Gorman, A. L. F., and M. V. Thomas (1980) Intracellular calcium accumulation during depolarization in a molluscan neurone. J. Physiol. (Lond.) 308: 259-285.

Hagiwara, S., and L. Byerly (1981) Calcium channel. Annu. Rev. Neurosci. 4: 69-125.

Hagiwara, S., S. Ozawa, and O. Sand (1975) Voltage clamp analysis of two inward current mechanisms in the egg cell membrane of a starfish. J. Gen. Physiol. 65: 617-644.

Hinrichsen, R. D., and Y. Saimi (1984) A mutation that alters properties of the calcium channel in Paramecium tetraaurelia. J. Physiol. (Lond.) 351:397-410.

Horn, R. (1978) Propagating calcium spikes in an axon of Aplysia. J. Physiol. (Lond.) 281: 513-534.

Johnson, J. W., and S. H. Thompson (1984) Mermbrane current of Aplysia neurons recorded from a large patch. Soc. Neurosci. Abstr. 10: 13.

Kado, R. T. (1973) Aplysia giant cell: Soma-axon voltage clamp current differences. Science 182: 843-845.

Kostyuk, P. G., and O. A. Krishtal (1977) Effects of calcium and calcium-chelating agents on the inward and outward current in the membrane of molluscan neurones. J. Physiol. (Lond.) 270: 569-580.

Kramer, R. S, and R. 7ucker (1985) Calcium-dependent inward current in Aplysia bursting pace-maker neurones. J. Physiol. (Lond.) 362. 107-130.

Lux, H. D., and A. M. Brown (1984) Patch and whole cell calcium current recorded simultaneously in snail neurons. J. Gen. Physiol. 83. $727-750$.

Matteson, D. R., and C. M. Armstrong (1986) Properties of two types of calcium channels in clonal pituitary cells. J. Gen. Physiol. 87: 161182.

McCleskey, E. W., A. P. Fox, D. Feldman, and R. W. Tsien (1986) Different types of calcium channels. J. Exp. Biol. 124: 177-190.
Miller, R. J. (1987) Multiple calcium channels and neuronal function. Science 235: 46-52.

Mirolli, M., and A. F. L. Gorman (1973) The extracellular space of a simple molluscan nervous system. J. Exp. Biol. 58: 423-435.

Mirolli, M., and S. R. Talbott (1972) The geometrical factors determining the electrotonic properties of a molluscan neurones. J. Physiol. (Lond.) 227: 19-34.

Narahashi, T., A. Tsunoo, and M. Yoshii (1987) Characterization of two types of calcium channels in mouse neuroblastoma cells. J. Physiol. (Lond.) 383: 231-250.

Neher, E. (1971) Two fast transient current components during voltage clamp on snail neurons. J. Gen. Physiol. 58: 36-53.

Neher, E., and H. D. Lux (1969) Voltage clamp on Helix pomatia neuronal membrane; current measurement over a limited area of the soma surface. Pfluegers Arch. 311: 272-277.

Nowycky, M. C., A. P. Fox, and R. W. Tsien (1985) Three types of neuronal calcium channels with different calcium agonist sensitivity. Nature 316: 440-443.

Palti, Y. (1971) Varying potential control voltage clamp of axons. In Biophysics and Physiology of Excitable Membranes, W. J. Adelman, Jr., ed., pp. 194-197, Van Nostrand Reinhold, New York.

Poo, M. M. (1985) Mobility and localization of proteins in excitable membranes. Annu. Rev. Neurosci. 8: 369-406.

Scheffey, C. E. (1975) The spatial distribution of transmembrane ionic currents on the surfaces of Helix aspersa giant neurons and the opercular membrane of Sarotherodon mossambicus. Ph.D dissertation, University of California, Berkeley, CA.

Smith, S. J., and S. H. Thompson (1987) Slow membrane currents in bursting pace-maker neurones of Tritonia. J. Physiol. (Lond.) 382: 425-448.

Strickholm, A. (1961) Impedance of a small electrically isolated area of the muscle cell surface. J. Gen. Physiol. 44: 1073-1088.

Stuhmer, W., W. M. Roberts, and W. Almers (1983) The loose patch clamp. In Single Channel Recording, B. Sakmann and E. Neher, eds., pp. 123-132, Plenum, New York.

Thompson, S. H. (1977) Three pharmacologically distinct potassium channels in molluscan neurones. J. Physiol. (Lond.) 265: 465-488.

Thompson, S., and J. Coombs (1986) Spatial distribution and kinetic differences of $\mathrm{Ca}^{++}$currents across the soma membrane in molluscan neurons. Soc. Neurosci. Abstr.

Thompson, S., S. J. Smith, and J. W. Johnson (1986) Slow outward tail currents in molluscan bursting neurons: Two components differing in temperature sensitivity. J. Neurosci. 11:3169-3176.

Tillotson, D. (1979) Inactivation of Ca conductance dependent on entry of Ca ions in molluscan neurons. Proc. Natl. Acad. Sci. USA 77: 1497-1500.

Tillotson, D., and A. L. F. Gorman (1980) Non-uniform $\mathrm{Ca}^{2+}$ buffer distribution in a nerve cell body. Nature 286: 816-817.

Tsien, R. W. (1983) Calcium channels in excitable cell membranes. Annu. Rev. Physiol. 45: 341-358.

Waxman, S. G., and J. M. Ritchie (1985) Organization of ion channels in the myelinated nerve fiber. Science 228: 1502-1507. 